\title{
Improved production of lutein and $\beta$-carotene by thermal and light intensity upshifts in the marine microalga Tetraselmis sp. CTP4
}

\author{
Lisa M. Schüler ${ }^{\mathrm{a}}$, Tamára Santos ${ }^{\mathrm{a}}$, Hugo Pereira ${ }^{\mathrm{a}}$, Paulo Duarte ${ }^{\mathrm{a}}$, Katkam N. Gangadhar ${ }^{\mathrm{a}}$, \\ Cláudia Florindo ${ }^{\mathrm{b}}$, Peter S.C. Schulze ${ }^{\mathrm{c}}$, Luísa Barreira ${ }^{\mathrm{a}}$, João C.S. Varela ${ }^{\mathrm{a}, *}$ \\ ${ }^{a}$ Centre of Marine Sciences, University of Algarve, Campus de Gambelas, 8005-139 Faro, Portugal

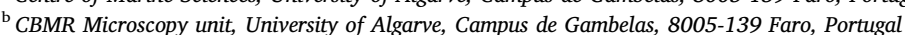 \\ ${ }^{\mathrm{c}}$ Nord university, Faculty of Biosciences and Aquaculture, 8049 Bodø, Norway
}

\section{A R T I C L E I N F O}

\section{Keywords:}

Marine microalgae

Carotenoids

Short-term stress

RP-HPLC

Carotenoid autofluorescence, nitrate repletion

\begin{abstract}
A B S T R A C T
The industrial microalga Tetraselmis sp. CTP4 is a promising candidate for aquaculture feed, novel food, cosmeceutical and nutraceutical due to its balanced biochemical profile. To further upgrade its biomass value, carotenogenesis was investigated by testing four environmental factors, namely temperature, light intensity, salinity and nutrient availability over different growth stages. The most important factor for carotenoid induction in this species is a sufficient supply of nitrates leading to an exponential growth of the cells. Furthermore, high temperatures of over $30^{\circ} \mathrm{C}$ compared to lower temperatures $\left(10\right.$ and $20^{\circ} \mathrm{C}$ ) induced the accumulation of carotenoids in this species. Remarkably, the two different branches of carotenoid synthesis were regulated depending on different light intensities. Contents of $\beta$-carotene were 3 -fold higher under low light intensities $\left(33 \mu \mathrm{mol} \mathrm{m}{ }^{-2} \mathrm{~s}^{-1}\right)$ while lutein contents increased 1.5-fold under higher light intensities (170 and $\left.280 \mu \mathrm{mol} \mathrm{m} \mathrm{m}^{-2} \mathrm{~s}^{-1}\right)$. Nevertheless, highest contents of carotenoids $\left(8.48 \pm 0.47 \mathrm{mg} \mathrm{g}^{-1} \mathrm{DW}\right)$ were found upon a thermal upshift from $20^{\circ} \mathrm{C}$ to $35^{\circ} \mathrm{C}$ after only two days at a light intensity of $170 \mu \mathrm{mol} \mathrm{m}^{-2} \mathrm{~s}^{-1}$. Under these conditions, high contents of both lutein and $\beta$-carotene were reached accounting for $3.17 \pm 0.18$ and $3.21 \pm 0.18 \mathrm{mg} \mathrm{g}^{-1} \mathrm{DW}$, respectively. This study indicates that Tetraselmis sp. CTP4 could be a sustainable source of lutein and $\beta$-carotene at locations where a robust, euryhaline, thermotolerant microalgal strain is required.
\end{abstract}

\section{Introduction}

In recent years, consumer interest in healthy food and natural products has been growing due to a rising awareness that a healthy nutrition can increase life expectancy. Evidence has been put forward that ingredients used as nutraceuticals and cosmeceuticals may confer additional health and medical benefits such as a decreased risk for chronic disease or cancer [1]. In turn, this has led to research efforts for the development of food supplements and cosmetics from natural sources. Microalgae are promising biological resources that meet these market needs due to their well-balanced biochemical profile as well as antioxidant, anticancer and anti-inflammatory activities [2]. Furthermore, microalgae can be cultivated in bioreactors or ponds placed on non-arable land, for example, deserts or shorelines, thus not competing with plant production. Moreover, they also display higher productivities than land crops [3].

One important group of bioactive compounds produced by microalgae are carotenoids. These molecules play essential roles as accessory light harvesting pigments and photoprotective agents, being also structural components of the light harvesting complexes of microalgae [4]. Their typical polyene structure is responsible for their lipophilic character, and the absence or presence of oxygenated groups defines two different carotenoid sub-classes, namely carotenes (e.g., $\alpha$ and $\beta$-carotene) and xanthophylls (e.g., lutein and violaxanthin), respectively. Furthermore, because of the presence of conjugated double bonds in their chemical structure, carotenoids not only have different colors, ranging from yellow to red, but also display antioxidant activities [5]. Carotenoids can scavenge reactive oxygen species (ROS), a well-known group of chemicals that can cause oxidative stress [6]. Because of their diverse roles, and aside from the genetics of a particular strain, carotenogenesis in microalgae is highly influenced by the environmental conditions to which the microalgal cells are exposed. Thus, culture conditions such as light intensity, nutrient availability, temperature and salinity may influence carotenoid contents. In the case

\footnotetext{
* Corresponding author.

E-mail address: jvarela@ualg.pt (J.C.S. Varela).
} 
A

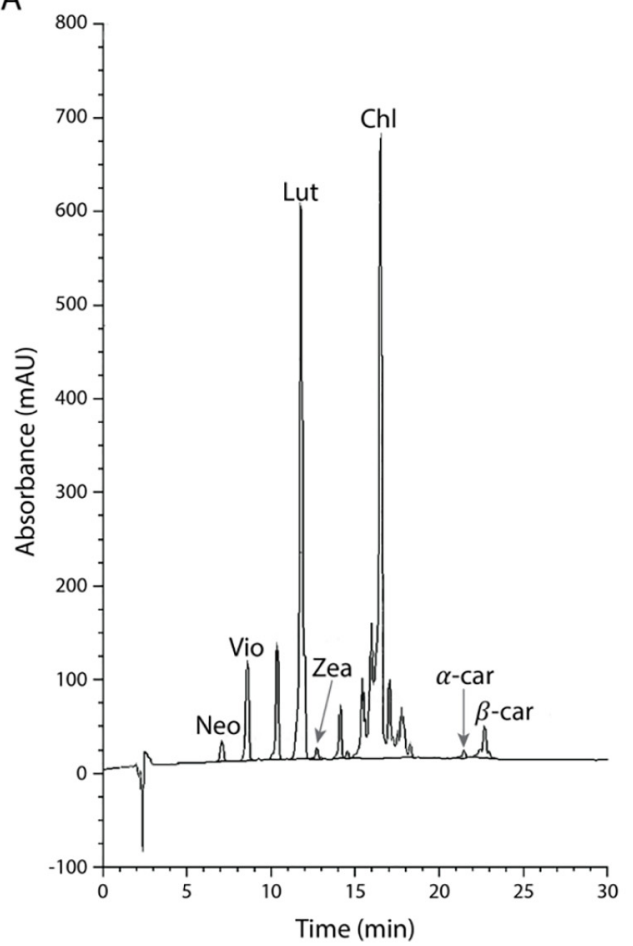

B

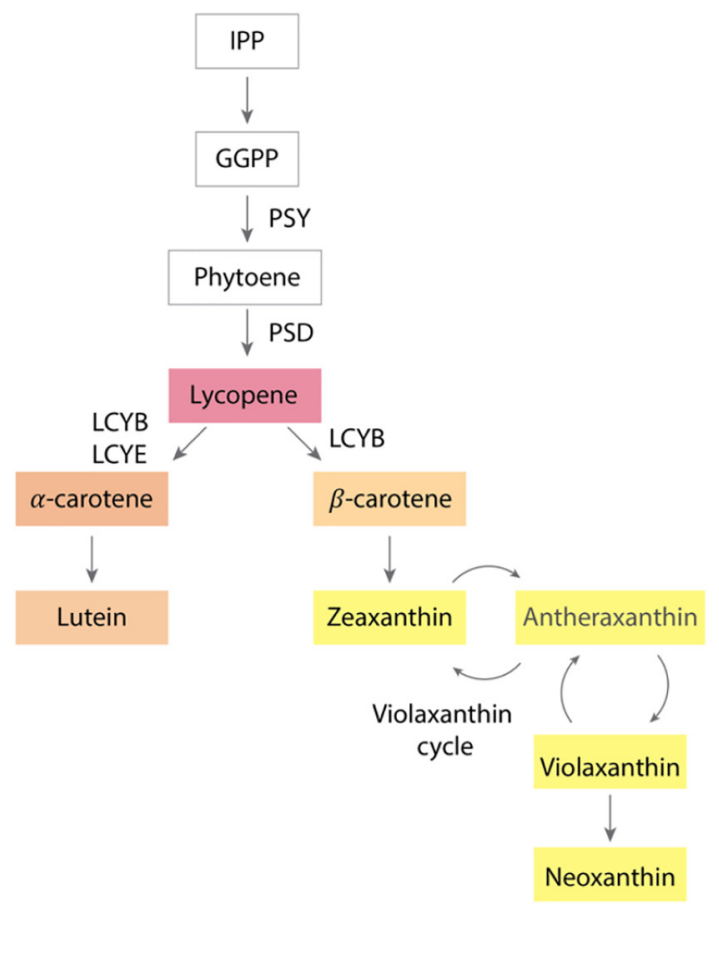

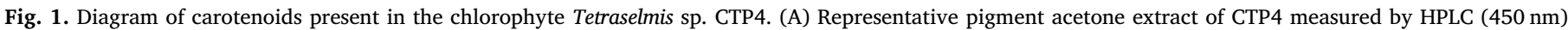

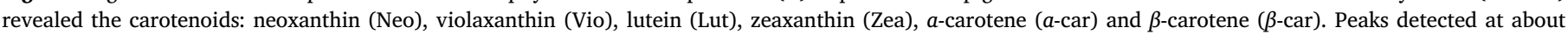

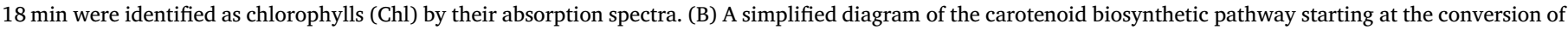

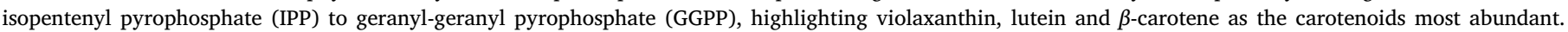

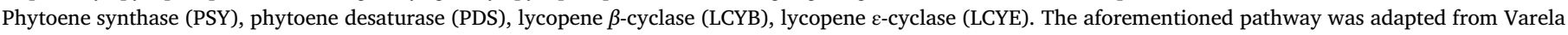
et al. [4].

of the chlorophytes Dunaliella salina and Haematococcus pluvialis, carotenogenesis is induced by high light intensity and/or nutrient depletion [7]. Under these conditions, the overproduction of these lipophilic carotenoids depends on triacylglycerol synthesis, which form lipid droplets and serve as a sink for carotenoid deposition [8]. However, other microalgae do not accumulate carotenoids in lipid droplets, but in the thylakoid membranes as carotenogenesis usually depends on growth-promoting conditions rather than on abiotic stress.

Microalgae belonging to the genus Tetraselmis are known for their great variety in carotenoids such as $\beta$-carotene, lutein and violaxanthin [9]. Even though Tetraselmis biomass is usually used in aquaculture feeds, recently the European Union approved the human consumption of biomass from a microalga of this genus as "novel food" [10]. Moreover, the inclusion of microalgal products in the human diet has been suggested, not only because of their comparable levels of carotenoids with those of vegetables, but also due to their antioxidant and cell-repairing activities against human lung cancer [11,12].

Recently, a robust marine microalga Tetraselmis sp. CTP4 was isolated displaying high growth rates and the ability to outcompete contaminants [13]. Remarkably, this microalga can withstand temperatures ranging from 5 to $40^{\circ} \mathrm{C}$, being able to grow in wastewater as well as seawater with salinities of up to $75 \%$ (data not shown). All these properties allowed for the successful scale-up to industrial photobioreactors of this robust microalgal strain (Pereira et al., 2018). In addition, because this microalga becomes predominantly unflagellated at later growth stages, a low-cost harvesting step in a settling tank driven by natural sedimentation was also implemented [14]. Furthermore, the wet biomass of this microalga showed significant amounts of extractable carotenoids when using acetone and glass-bead milling (L. Schüler, L. Barreira, J. Varela, unpublished results).

In this study, carotenoid profiles of Tetraselmis sp. CTP4 were investigated under four abiotic growth factors, namely light intensity, temperature, salinity, nitrate repletion or depletion during different growth stages. Even though few studies have focused on the induction of carotenoids by abiotic stress factors in microalgae belonging to this genus, this is the first thorough report dissecting the interaction of these growth conditions [15-19]. The aim of this study is to provide knowledge of how carotenoid biosynthesis is regulated in Tetraselmis microalgae and where carotenoids accumulate in this chlorophyte. Furthermore, a cultivation strategy is suggested to obtain carotenoidrich biomass, which could be applicable not only in aquaculture but also as novel food or cosmeceutical.

\section{Materials and methods}

\subsection{Organism, standard growth conditions and harvesting}

The microalga Tetraselmis sp. CTP4 was isolated from Ria Formosa in Portugal as described in Pereira et al. (2016). Standard growth conditions were established in previous reports $[13,20]$. Briefly, initial microalgal cultures were grown in 5-L reactors $(\varnothing=12 \mathrm{~cm})$ using sterilized Atlantic seawater from the shoreline of Faro, Portugal (salinity $\sim 35 \%$ ) enriched with Modified Algal Medium (MAM) containing $27.2 \mathrm{mg} \mathrm{N}-\mathrm{NO}_{3}{ }^{-} \mathrm{L}^{-1}$ at $20{ }^{\circ} \mathrm{C}$ with a photon flux density (PFD) of $100 \mu \mathrm{mol} \mathrm{m}^{-2} \mathrm{~s}^{-1}$ and aeration of the cultures by $0.2 \mu \mathrm{m}$-filtered air for 10 days. After this 10-day growth period, nitrate content was found to be almost depleted $\left(0.75 \mathrm{mg} \mathrm{N}-\mathrm{NO}_{3}{ }^{-} \mathrm{L}^{-1}\right)$ and cultures were used as inoculum for abiotic stress experiments. All experiments were performed using biological triplicates in a growth chamber (Radiber, SA, Spain) to ensure that a stable temperature was achieved. Horizontally mounted LED strips (LEDUP, SMD 5050, $6000 \mathrm{~K}, 10.8 \mathrm{~W} \mathrm{~m}^{-1}$, Teclusa, Portugal) supplied constant illumination of the cultures and light intensity was measured with a micro quantum sensor (Model US-MQS-B, Walz, Effeltrich, Germany). After the incubation periods, cultures were 

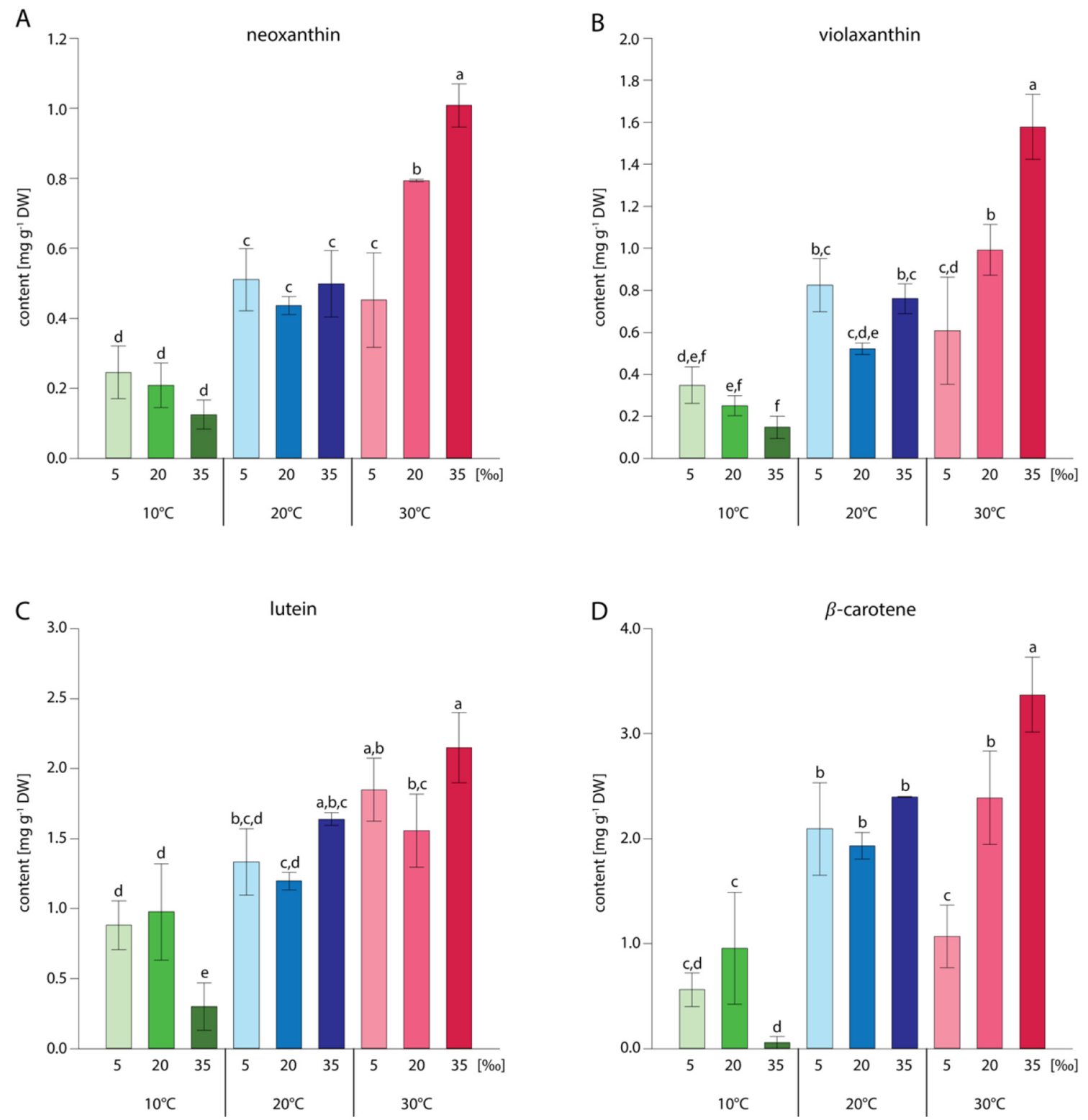

Fig. 2. Influence of temperature and salinity on carotenoid content of Tetraselmis sp. CTP4. Cultures were inoculated in 5-L reactors containing different salinities of 5,20 and $35 \%$ and grown at 5,20 and $30{ }^{\circ} \mathrm{C}$ with a light intensity of $100 \mu \mathrm{mol} \mathrm{m}^{-2} \mathrm{~s}^{-1}$ until stationary phase $(n=3$, average \pm SD). Carotenoid extracts were analyzed by HPLC and neoxanthin (A), violaxanthin (B), lutein (C) and $\beta$-carotene (D) were quantified. Different letters over the bars indicate significant differences $(p<0.05)$ using two-way ANOVA with post hoc Tukey HSD test.

harvested by centrifugation $(5000 \mathrm{~g}, 5 \mathrm{~min})$; pellets and supernatants were kept frozen at $-20^{\circ} \mathrm{C}$ until further analysis.

\subsection{Culture conditions for abiotic stress on carotenoid induction}

\subsubsection{Effect of temperature and salinity}

Cultures were inoculated in 5-L reactors $(\varnothing=13 \mathrm{~cm})$ containing different salinities (5, 20 and 35\%), which were achieved by diluting the seawater with distilled water. After supplementation with MAM, cultures were grown at 5,20 or $30^{\circ} \mathrm{C}$ with a PFD of $100 \mu \mathrm{mol} \mathrm{m}^{-2} \mathrm{~s}^{-1}$ until early stationary phase.

\subsubsection{Effect of light intensity and nitrate availability}

This experiment was performed in 100-mL glass photobioreactors $(\emptyset=3 \mathrm{~cm}$ ), filled up with culture to a volume of $80 \mathrm{~mL}$. All cultures were inoculated with a biomass concentration of $0.3 \mathrm{~g} \mathrm{~L}^{-1}$ and grown in seawater with a salinity of $35 \%$ supplemented with MAM without nitrate. A solution of $\mathrm{NaNO}_{3}$ was added to half of the cultures to achieve a final concentration of $97 \mathrm{mg} \mathrm{N}-\mathrm{NO}_{3}{ }^{-} \mathrm{L}^{-1}(\mathrm{~N}+$, nitrogen replete), whereas the other half were incubated without additional nitrate $(\mathrm{N}-$, nitrogen depleted). During this growth period, three different PFDs were applied: 33,170 and $280 \mu \mathrm{mol} \mathrm{m}^{-2} \mathrm{~s}^{-1}$. Cultures were incubated at $30^{\circ} \mathrm{C}$ and samples were taken after 2,5 and 10 days.

\subsubsection{Effect of short-term induction at high temperature}

This experiment was performed under the same conditions as the previous experiment with the following modifications. All cultures were inoculated with a biomass concentration of $0.6 \mathrm{~g} \mathrm{~L}^{-1}$ and were incubated at $35^{\circ} \mathrm{C}$ using two different PFDs: 33 and $170 \mu \mathrm{mol} \mathrm{m}^{-2} \mathrm{~s}^{-1}$. Samples were taken after 2 and 5 days.

\subsection{Microscopy}

For microscopy, samples were taken from cultures grown at high 

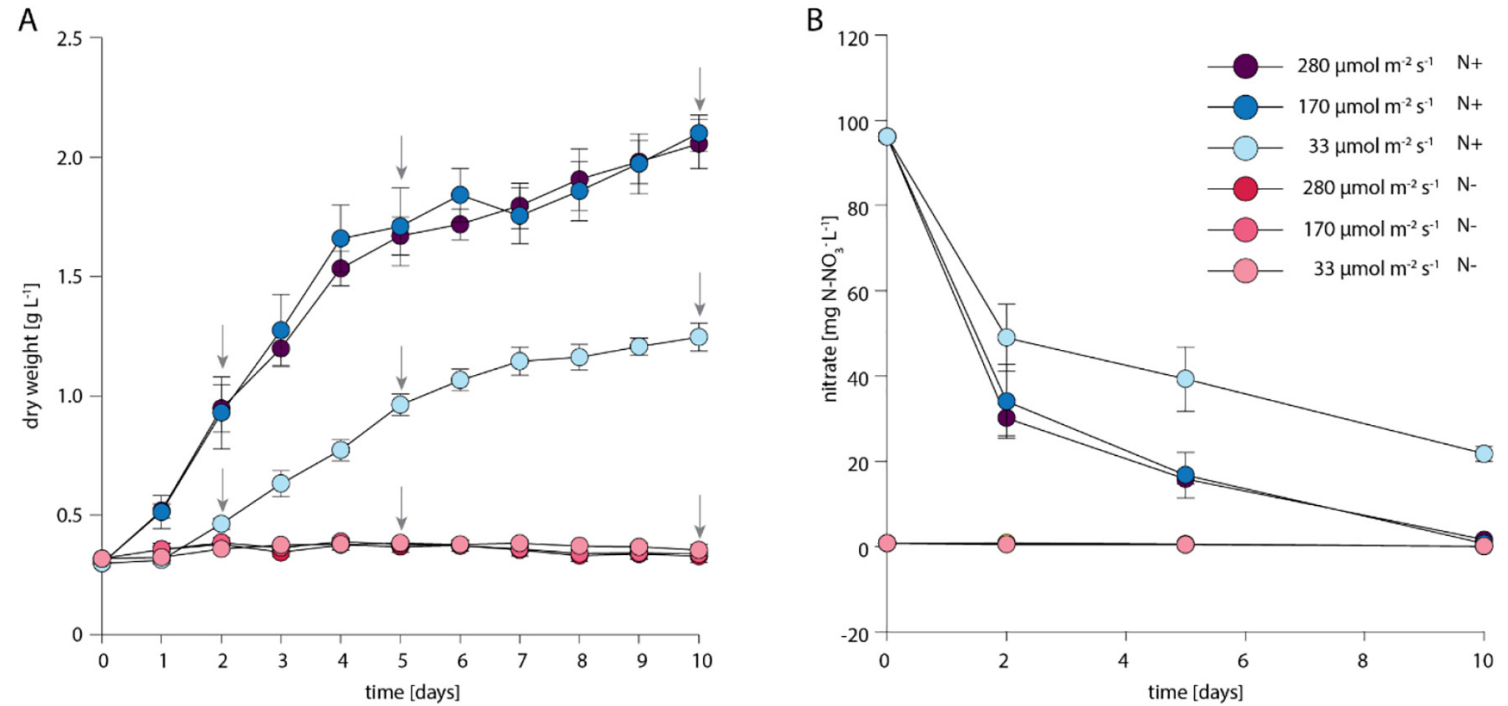

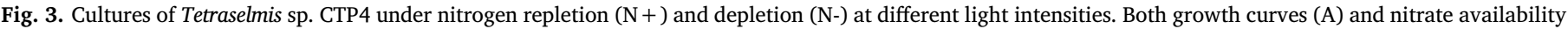
(B) are shown $(n=3$, average $\pm \mathrm{SD})$. Arrows on the growth curves indicate the harvesting time points of the biomass for carotenoid and nitrate analysis.

temperature $\left(35^{\circ} \mathrm{C}\right)$ under nitrogen repletion or nitrogen depletions during a period of 5 days. Images were acquired with a Zeiss AXIOMAGES Z2 microscope, equipped with a coollSNApHQ2 camera and AxioVision software version 4.8 (Carl Zeiss MicroImaging GmbH, Göttingen, Germany), using a $100 \times$ magnification. For fluorescence imaging, a Zeiss 38 HE filter set (ex. $470 / 40 \mathrm{~nm}$, em. 525/50 nm) was used (Carl Zeiss MicroImaging GmbH, Göttingen, Germany) and the transmitted light images were acquired using differential interference contrast (DIC). Images were treated using Image $\mathrm{J}$ software (Research Service Branch, NIH, Bethesda, MD).

\subsection{Analytical methods}

\subsubsection{Determination of growth by optical density and dry weight}

To monitor cell growth and biomass concentration, the optical density was measured in 96 -well plates at $750 \mathrm{~nm}\left(\mathrm{OD}_{750}\right)$ and the dry weight was determined as described previously [13,20]. Briefly, dry weight (DW) was determined by filtering a 2-ml sample of each culture through a pre-washed and pre-weighed glass microfiber filter $(0.47 \mu \mathrm{m})$, washed with $20 \mathrm{~mL}$ of ammonium formate $\left(31.5 \mathrm{~g} \mathrm{~L}^{-1}\right)$ and dried at $60^{\circ} \mathrm{C}$ until constant weight. A significant correlation $(r \geq 0.96$, $p<0.01$ ) between $\mathrm{OD}_{750}$ and DW was found using biomass from different growth conditions $(n=55)$. For the calculation of the DW used in carotenoid extraction, the following Eq. (1) was used:

$\mathrm{DW}\left[\mathrm{g} \mathrm{L}^{-1}\right]=1.6101 * \mathrm{OD}_{750}$

\subsubsection{Determination of nitrate concentration}

Nitrate concentration was determined by the UV spectrophotometric method as described in [20].

\subsubsection{Carotenoid extraction and quantification}

Carotenoids were extracted from wet biomass by resuspending a biomass sample of about $2 \mathrm{mg}$ in $3 \mathrm{~mL}$ of acetone under dimmed light to avoid oxidation. After the addition of $0.7 \mathrm{~g}$ of glass beads $(425-600 \mu \mathrm{m})$, the tubes were vortexed using an IKA Vortex Genius 3 at maximum speed for $2 \mathrm{~min}$ to lyse the cells. To collect the supernatant, the samples were centrifuged for $8 \mathrm{~min}$ at $8000 \mathrm{~g}$. The extraction procedure was repeated until both the pellet and the supernatant became colorless. After evaporation of acetone under a gentle nitrogen flow, the extracts were resuspended in $700 \mu \mathrm{L}$ of methanol and filtrated through $0.22 \mu \mathrm{m}$ PTFE filter to remove suspended particles.

The carotenoids present in the extract were identified and quantified by HPLC. The Dionex 580 HPLC System (DIONEX Corporation, United States) consisted of a PDA 100 Photodiode-array detector, P680 Pump, ASI 100 Automated Injector and STH 585 column oven set to $20^{\circ} \mathrm{C}$. Separation of carotenoids was achieved with a LiChroCART RP-18 ( $5 \mu \mathrm{m}, 250 \times 4 \mathrm{~mm}$, LiChrospher) column using a $1 \mathrm{~mL} \mathrm{~min}^{-1}$ flow and a solvent program adapted from Couso et al. [21]. Briefly, the gradient mobile phase composed of solvent A acetonitrile:water $(9: 1 ; \mathrm{v} / \mathrm{v})$ and solvent $B$ ethyl acetate was applied as followed: 0-16 min, 0-60\% B; 16-30 min, 60\% B; 30-32 min 100\% B and $32-35 \mathrm{~min} 100 \% \mathrm{~A}$. All carotenoids were detected at $450 \mathrm{~nm}$ and analyzed with Chromeleon Chromatography Data System software (Version 6.3, ThermoFisher Scientific, Massachusetts, US). The quantification was carried out using calibration curves of neoxanthin, violaxanthin, lutein and $\beta$-carotene standards (Sigma-Aldrich, Portugal). Injection volume of both extracts and standards was $100 \mu \mathrm{L}$.

\subsection{Data treatment}

The carotenoid production was calculated as follows:

Production $\left[\mathrm{mg} \mathrm{L}^{-1} * \mathrm{~d}\right]=\left(\right.$ content $\left[\mathrm{mg} \mathrm{g}^{-1}\right] *$ biomass $\left.\left[\mathrm{g} \mathrm{L}^{-1}\right]\right) /$ time $[\mathrm{d}]$

Results were analyzed using SPSS (release 25.0, SPSS Inc., Chicago, IL) software without data treatment. Data was evaluated for normality (Shapiro-Wilk) and homogeneity of variances (Levene test). For the comparison of means (ANOVA), the Tukey HSD test for equal variances with a confidence interval of $95 \%$ was performed.

\section{Results and discussion}

\subsection{Carotenoid profile of Tetraselmis sp. CTP4}

The major carotenoids of the chlorophyte Tetraselmis sp. CTP4 were violaxanthin, lutein and $\beta$-carotene as detected by HPLC analysis of acetone extracts (Fig. 1A). Under the conditions used, microalgal cells also contained detectable amounts of neoxanthin, zeaxanthin and $\alpha$ carotene. These results thus suggest that this strain has two active branches of the carotenoid biosynthetic pathway (Fig. 1B): one giving rise to $\alpha$-carotene and lutein, and a second one leading to the biosynthesis of $\beta$-carotene and other high-value xanthophylls [22]. Both branches depend upon different lycopene cyclases that give rise to different intermediates [23]. For example, the branch yielding $\beta$ - 
A

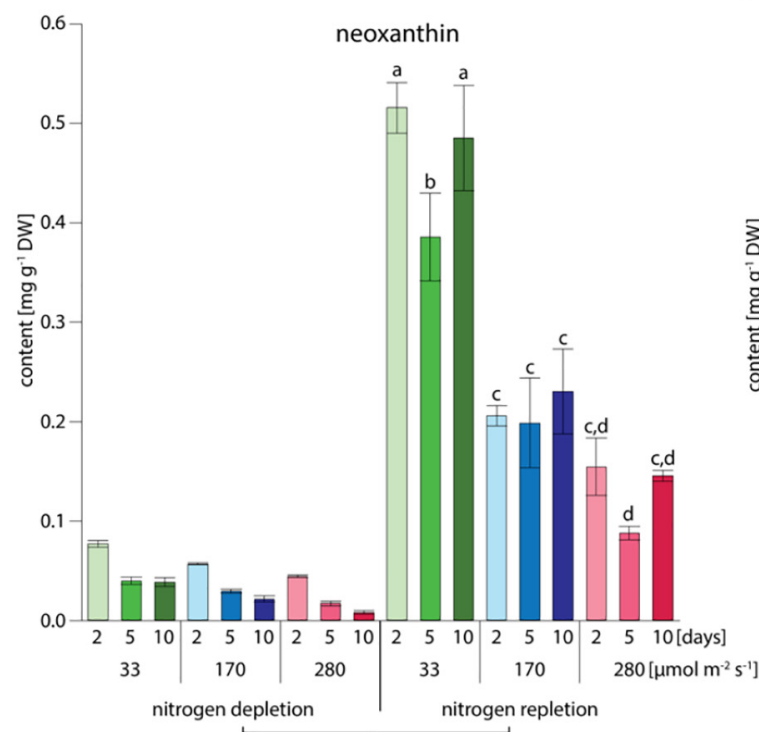

B

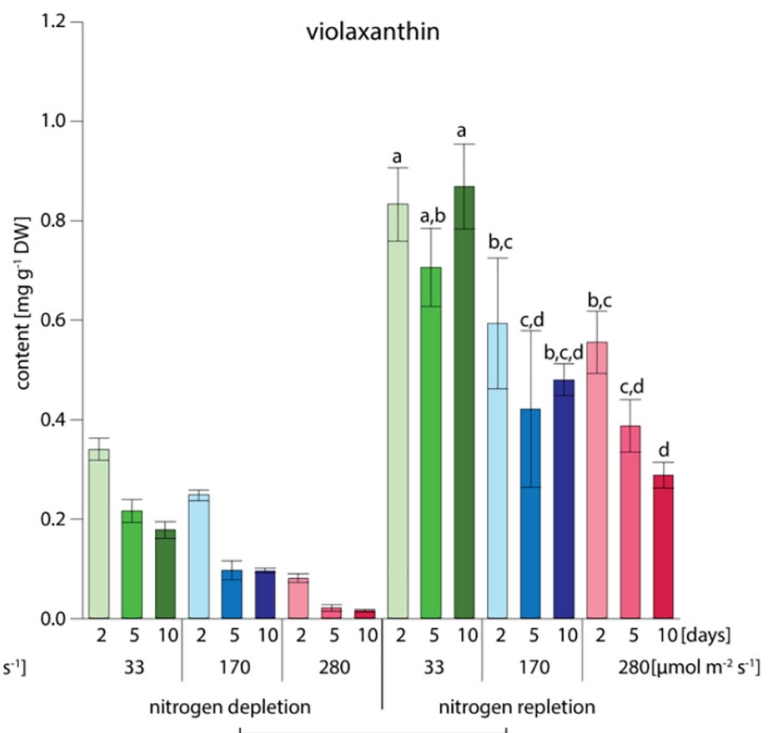

C
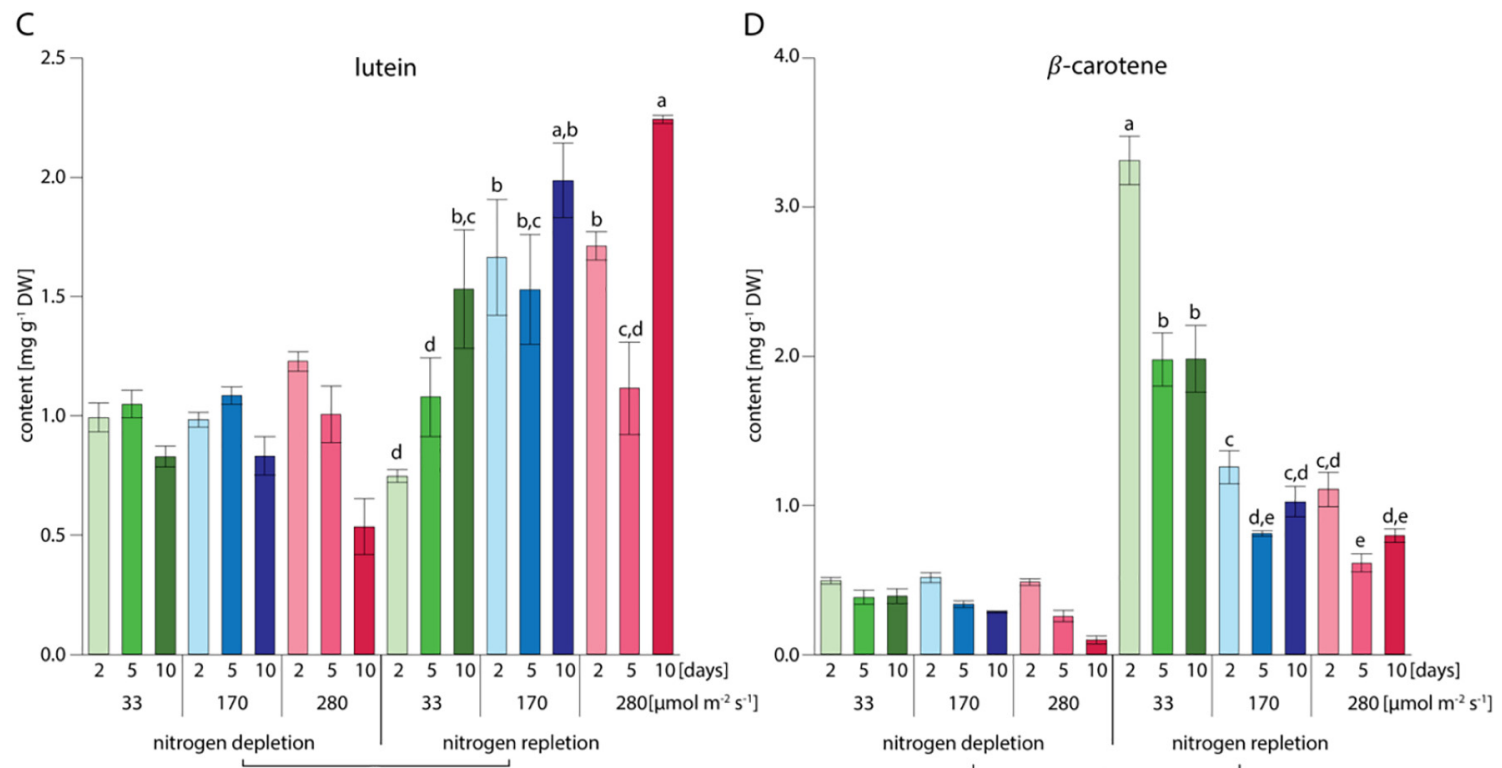

Fig. 4. Effect of light intensity and nutrient availability on the carotenoid contents of Tetraselmis sp. CTP4 at $30^{\circ} \mathrm{C}$. Cultures were supplemented with MAM without (nutrient depletion) or with (nutrient repletion) nitrate to a final concentration of $97 \mathrm{mg} \mathrm{N}-\mathrm{NO}_{3} \mathrm{~L}^{-1}$ and grown at light intensities of 33,170 and $280 \mu \mathrm{mol} \mathrm{m}{ }^{-2} \mathrm{~s}^{-1}$ $(n=3$, average \pm SD). Contents of neoxanthin (A), violaxanthin (B), lutein (C) and $\beta$-carotene (D) were quantified in the biomass harvested after 2,5 and 10 days of growth using RP-HPLC. Significant differences between carotenoid contents of cells under nitrogen depletion or repletion are indicated with an asterisk. For neoxanthin, violaxanthin, lutein and $\beta$-carotene a two-way ANOVA with post hoc Tukey HSD test was performed. Different letters over the bars indicate significant differences $(p<0.05)$.

carotene is known to generate zeaxanthin via a reaction of hydroxylation. This xanthophyll can be converted to antheraxanthin and then to violaxanthin by different reversible reactions, which are usually referred to as "the violaxanthin cycle" [4]. Therefore, the detection of violaxanthin in the biomass suggests that this photoprotective pathway may be active in this strain, as appears to be the case for many chlorophytes [24]. Interestingly, even though neoxanthin can be synthesized by the direct isomerization of violaxanthin, it was only found at minor concentrations in Tetraselmis sp. CTP4.

\subsection{Effect of temperature and salinity on carotenoid contents}

In order to understand what environmental conditions favored the induction of carotenogenesis in this microalga, the first abiotic factors addressed were temperature and salinity (Fig. 2). A temperature of $20^{\circ} \mathrm{C}$ and a salinity of $35 \%$ corresponded to "standard growth conditions" as used in previous studies on this strain $[13,20]$, under which the cells had contents of neoxanthin, violaxanthin, lutein and $\beta$-carotene of $0.5,0.76,1.64$, and $2.4 \mathrm{mg} \mathrm{g}^{-1} \mathrm{DW}$, respectively (Fig. 2). These amounts are similar or even higher than those reported in other Tetraselmis strains [9,12], except for one species that was isolated from tropical waters, which had lutein and $\beta$-carotene contents of 4.8 and $51.4 \mathrm{mg} \mathrm{g}^{-1} \mathrm{DW}$, respectively [18].

At $20^{\circ} \mathrm{C}$, salinity downshifts to as low as $5 \%$ did not significantly affect the carotenoid contents. A decrease in temperature to $10^{\circ} \mathrm{C}$, however, resulted in an overall 2-fold decrease in all pigments, regardless of the salinity, as compared to standard growth conditions (Fig. 2). At low temperatures, the nutrient uptake rate decreases and 
A

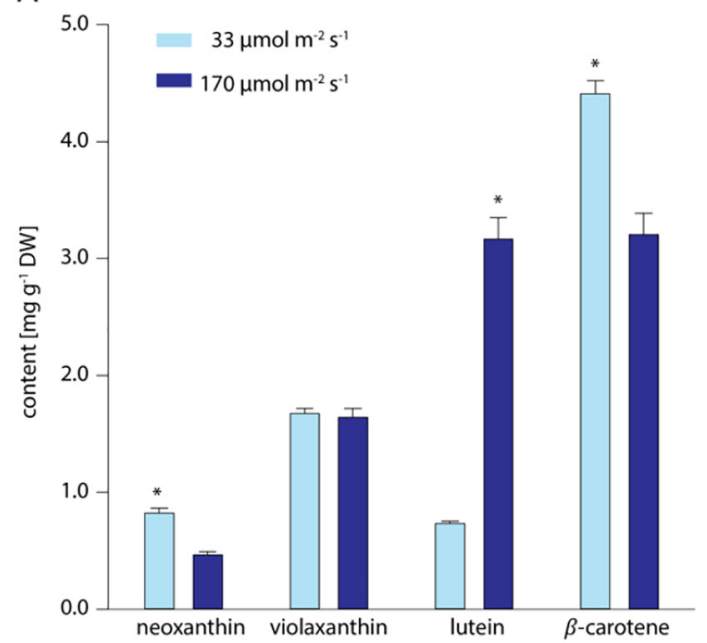

B

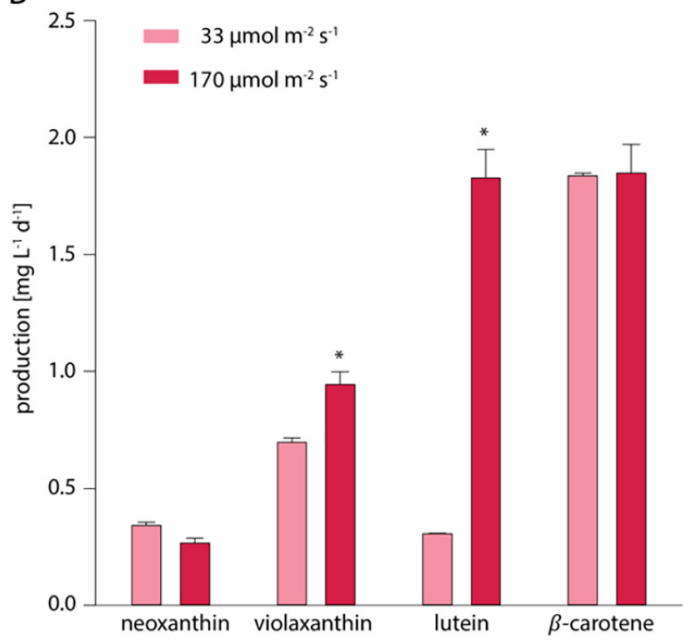

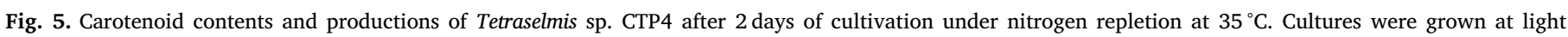

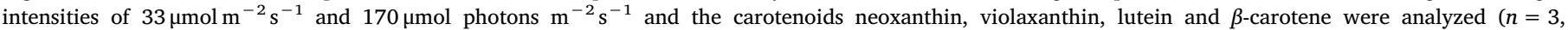
average \pm SD). Significant differences $(p<.05)$ between carotenoid contents (A) and productivities (B) are indicated with an asterisk.
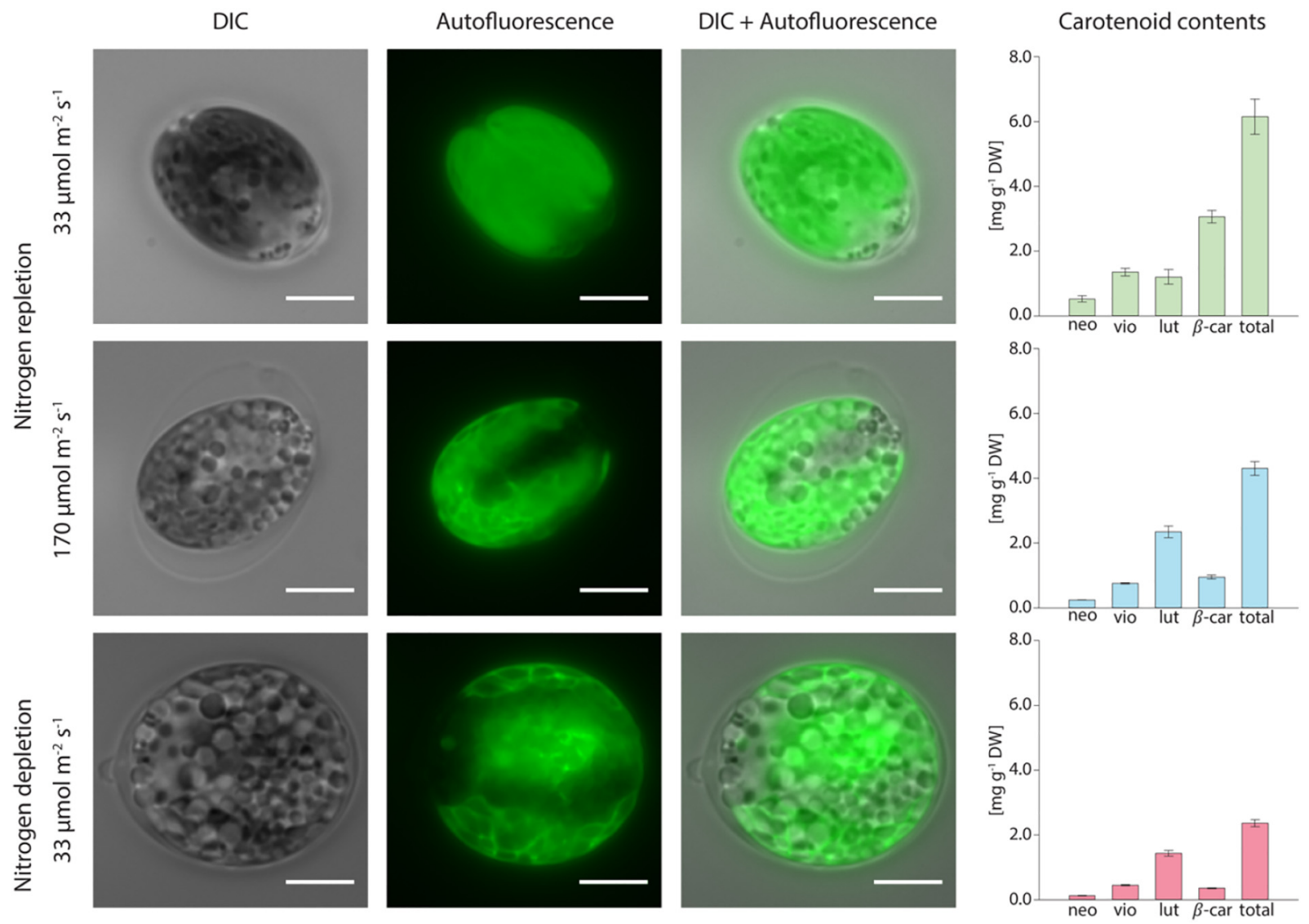

Fig. 6. Autofluorescence and carotenoid contents of Tetraselmis sp. CTP4 cells under different abiotic stressors. After incubation of the cultures for 5 days at $35^{\circ} \mathrm{C}$, neoxanthin (neo), violaxanthin (vio), lutein (lut) and $\beta$-carotene ( $\beta$-car) were analyzed. Furthermore, of the same samples, images were taken using differential interference contrast (DIC) and filter set $38 \mathrm{HE}$ (ex. $470 / 40 \mathrm{~nm}$, em. $525 / 50 \mathrm{~nm}$ ) for autofluorescence. Scale bar $=5 \mu \mathrm{m}$.

thus the metabolism slows down leading to lower amounts of carotenoids [25]. Indeed, lower growth rates of cultures grown at $10^{\circ} \mathrm{C}$ (data not shown) were observed. Remarkably, when carotenoid contents in cells cultivated at $30^{\circ} \mathrm{C}$ are compared, significant differences can be observed between cultures grown at different salinities for carotenoids produced by the $\beta$-carotene branch within the carotenoid biosynthetic pathway (Figs. 1B and 2). Remarkably, at this temperature, neoxanthin and violaxanthin contents increased about 2fold with increasing salinity, reaching a maximum of $1.01 \pm 0.06 \mathrm{mg} \mathrm{g}^{-1} \mathrm{DW}$ and $1.58 \pm 0.16$ at $35 \%$, respectively (Fig. 2A, B). In the case of $\beta$-carotene, cells at a salinity of $5 \%$ showed a 2 -fold decrease in the content of this pigment as compared to standard growth conditions. Conversely, at a salinity of $35 \%$, cells increased their $\beta$-carotene content to a maximum of $3.37 \pm 0.36 \mathrm{mg} \mathrm{g}^{-1} \mathrm{DW}$ 
(Fig. 2D). The increase in temperature, however, did not result in significant differences in lutein contents (Fig. 2C). Nevertheless, at a salinity of $35 \%$ and $30{ }^{\circ} \mathrm{C}$, lutein content reached the maximum of $2.15 \pm 0.25 \mathrm{mg} \mathrm{g}^{-1} \mathrm{DW}$. An increase in lutein contents with temperature has been observed in other microalgae such as Chlorella sorokiniana, Muriellopsis sp. and Scenedesmus almeriensis [26-28]. Xanthophylls are structural components in the thylakoid membrane and may help to stabilize the membranes upon thermal upshifts to maintain membrane fluidity, which is important for molecule exchange or the function of light harvesting complexes [29]. Furthermore, high salinity and heat stress are responsible for the accumulation of ROS, which can be scavenged by $\beta$-carotene and lutein [6]. In this study, the combined application of a temperature and salinity upshift led to the highest total carotenoid contents in Tetraselmis sp. CTP4 (8.11 $\left.\pm 0.61 \mathrm{mg} \mathrm{g}^{-1} \mathrm{DW}\right)$.

\subsection{Effect of light intensity and nitrogen availability on carotenoid contents}

As previous experiments have shown that a temperature of $30^{\circ} \mathrm{C}$ and a salinity of $35 \%$ are optimal for carotenoid induction, these parameters were maintained constant. Cultures under nitrogen depletion $\left(\mathrm{N}-, 0.75 \mathrm{mg} \mathrm{N}^{-N}{ }_{3}{ }^{-} \mathrm{L}^{-1}\right)$ remained at a plateau of about $0.4 \mathrm{~g} \mathrm{~L}^{-1}$ regardless of the light intensity over the incubation period of 10 days whereas cultures under nitrogen repletion $(\mathrm{N}+)$ showed exponential and/or linear growth (Fig. 3). At light intensities of 170 and $280 \mu \mathrm{mol} \mathrm{m} \mathrm{m}^{-2} \mathrm{~s}^{-1}$, cells grew exponentially with a very short lag phase during the first day. After 10 days, the highest biomass of $2.1 \mathrm{~g} \mathrm{~L}^{-1}$ was reached under both light intensities. At this time point, nitrates were completely consumed and cells entered into nitrogen starvation (Fig. 3B). At a lower light intensity $\left(33 \mu \mathrm{mol} \mathrm{m}{ }^{-2} \mathrm{~s}^{-1}\right)$, cells grew slower with a longer lag phase in the first two days. After 10 days, the biomass rose up to $1.25 \mathrm{~g} \mathrm{~L}^{-1}$ and a nitrate concentration of $21.75 \mathrm{mg} \mathrm{N}^{-N}{ }_{3}{ }^{-} \mathrm{L}^{-1}$ was still present in the media.

Regarding carotenoid contents, the most decisive factor was nitrogen availability, as cells under nitrogen repletion showed on average total carotenoid contents 2.5 -fold higher than those of cells under nutrient depletion (Fig. 4). Enhanced carotenoid contents under nitrogen repletion is in agreement with studies on other Tetraselmis species [16-18]. The importance of, for example, nitrogen availability for carotenogenesis may be due to the connection with the synthesis of proteins of the light harvesting complex that bind, among others, to carotenoids [24]. Even though this microalga accumulated high lipid contents of up to $30 \%$ of its DW under nitrogen depletion, this condition did not promote the accumulation of carotenoids [13]. On the contrary, the observed decreased contents of carotenoids under nitrogen depletion may be the result of reduced metabolic and photosynthetic activity of the cells. Interestingly, the contents of lutein in N-starving cells levelled at about $0.95 \mathrm{mg} \mathrm{g}^{-1} \mathrm{DW}$ throughout the experiment (Fig. 4C). This result suggests that this xanthophyll is perhaps one of the most important carotenoids, particularly when this alga is under stress. Lutein has been proposed to be an important photoprotective pigment with a scavenging role in cells under these conditions [21]. When comparing different microalgal cultures grown at different light intensities, total carotenoid contents were 1.5-fold higher in cells at a low light intensity $\left(33 \mu \mathrm{mol} \mathrm{m} \mathrm{m}^{-2} \mathrm{~s}^{-1}\right)$ compared to those under a higher light intensity $\left(170 \mu \mathrm{mol} \mathrm{m}^{-2} \mathrm{~s}^{-1}\right)$. The induction of carotenoids under low light conditions could be due to a larger chloroplast and the need for a more efficient light utilization [30]. The xanthophylls neoxanthin and violaxanthin were found to be up to 3-fold higher in cells grown under these lower light conditions than under higher light (Fig. 4B). Furthermore, the content of $\beta$-carotene was up to 3 -fold higher in cells at low light $\left(33 \mu \mathrm{mol} \mathrm{m}{ }^{-2} \mathrm{~s}^{-1}\right)$ as compared to those under higher light intensities, most probably due to its role as a light harvesting pigment under this lower light intensity (Fig. 4D). Lutein contents, however, were 1.5-fold higher under higher light intensities (170 and $280 \mu \mathrm{mol} \mathrm{m}^{-2} \mathrm{~s}^{-1}$ ) than under lower light (Fig. 4C) in cells under nutrient repletion. Conversely, this was not observed in cells under nutrient starvation.

Taken together, these results seem to highlight once more the role of lutein as a photoprotective pigment in actively growing Tetraselmis cells. However, the observed increase in the intracellular lutein levels is apparently inhibited in starved microalgal cultures. These observations are in agreement with studies on C. sorokiniana $\left(3.1 \mathrm{mg}\right.$ lutein $\mathrm{g}^{-1} \mathrm{DW}$ at $690 \mu \mathrm{mol} \mathrm{m}^{-2} \mathrm{~s}^{-1}$ ) and Muriellopsis sp. (0.51 pg lutein cell ${ }^{-1}$ at $460 \mu \mathrm{mol} \mathrm{m}^{-2} \mathrm{~s}^{-1}$ ), where lutein contents increased with increasing light intensity in actively growing cultures [26,28].

Furthermore, the incubation period influenced the carotenoid contents. Already after 2 days of incubation at a light intensity of $33 \mu \mathrm{mol} \mathrm{m}{ }^{-2} \mathrm{~s}^{-1} \quad \beta$-carotene content reached a maximum of $3.31 \pm 0.16 \mathrm{mg} \mathrm{g}^{-1} \mathrm{DW}$, followed by a significant decrease after 5 and 10 days of incubation to $1.98 \pm 0.2 \mathrm{mg} \mathrm{g}^{-1} \mathrm{DW}$ (Fig. 4D). A similar response was observed for violaxanthin and neoxanthin contents, which were highest 2 days after a downshift of the light intensity to $33 \mu \mathrm{mol} \mathrm{m}{ }^{-2} \mathrm{~s}^{-1}\left(0.87 \pm 0.09 \mathrm{mg} \mathrm{g}^{-1} \mathrm{DW}\right.$ and $0.52 \pm 0.03 \mathrm{mgg}^{-1}$ DW, respectively). Lutein contents at low light intensities of $33 \mu \mathrm{mol} \mathrm{m}{ }^{-2} \mathrm{~s}^{-1}$ increased with increasing incubation time reaching $1.53 \pm 0.25 \mathrm{mg} \mathrm{g}^{-1} \mathrm{DW}$ after 10 days (Fig. 4C). These contents at low light intensities are similar to those obtained previously (Fig. 2), which leads to the assumption that the actual light intensity in the larger photobioreactors ( $5 \mathrm{~L}$ ) was sensed as low light by the cells. The observed increase in carotenoid levels after 2 days may be a short-term acclimation response to the new growth conditions. At low light, $\beta$ carotene is apparently the most important pigment due to its double role in light harvesting and ${ }^{1} \mathrm{O}_{2}$ quenching, while at higher light intensities lutein becomes the main carotenoid. After 5 days of incubation, the cells seemed to have become acclimated to the new environment, ceasing carotenoid biosynthesis, so that most of the carbon (and energy) is used in growth and cell division, resulting in the observed drop in carotenoid contents. After 10 days, however, when the cultures reach high cell concentrations and nitrates became limiting (Fig. 3), carotenoid contents tend to rebound, in particular at the highest light intensity used, probably due to their role in photoprotection. Highest contents of lutein were observed at this time point, reaching a maximum of $2.24 \pm 0.02 \mathrm{mg} \mathrm{g}^{-1} \mathrm{DW}$ at higher light intensities of $280 \mu \mathrm{mol} \mathrm{m}{ }^{-2} \mathrm{~s}^{-1}$. In a previous study on lutein production by Scenedesmus obliquus, the highest contents of this xanthophyll $\left(4.75 \pm 1.69 \mathrm{mg} \mathrm{g}^{-1} \mathrm{DW}\right)$ were also observed at the beginning of nitrogen depletion at a light intensity of $150 \mu \mathrm{mol} \mathrm{m}^{-2} \mathrm{~s}^{-1}$ [31].

\subsection{Short-term induction of lutein and $\beta$-carotene upon a thermal upshift}

As previous experiments showed that high temperature $\left(30^{\circ} \mathrm{C}\right)$, nutrient repletion and an incubation period of only 2 days were sufficient to achieve high contents of neoxanthin, violaxanthin, lutein and $\beta$ carotene, cells were further exposed to an even higher temperature $\left(35^{\circ} \mathrm{C}\right)$ for a period of only 2 days (Fig. 5). Interestingly, carotenoid contents $\left(8.48 \pm 0.47 \mathrm{mg} \mathrm{g}^{-1} \mathrm{DW}\right)$ increased under these conditions compared with previous experiments (Fig. 4). Indeed, the contents of neoxanthin and $\beta$-carotene were highest at a light intensity of $33 \mu \mathrm{mol} \mathrm{m}{ }^{-2} \mathrm{~s}^{-1}\left(0.82 \pm 0.04\right.$ and $4.41 \pm 0.12 \mathrm{mg} \mathrm{g}^{-1} \mathrm{DW}$, respectively, Fig. 5A). Conversely, the lutein content $\left(3.17 \pm 0.18 \mathrm{mg} \mathrm{g}^{-1}\right.$ DW) was highest at the highest light intensity $\left(170 \mu \mathrm{mol} \mathrm{m}^{-2} \mathrm{~s}^{-1}\right)$ tested (Fig. 5A). Contents of violaxanthin $\left(1.67 \pm 0.04 \mathrm{mg} \mathrm{g}^{-1} \mathrm{DW}\right)$ did not show significant differences between the treatments. These results confirm the trends observed earlier (Figs. 2 and 4). However, when productions are compared, no significant difference for neoxanthin and $\beta$-carotene can be found between cells at both light intensities $\left(0.34 \pm 0.01\right.$ and $1.85 \pm 0.12 \mathrm{mg} \mathrm{L}^{-1} \mathrm{~d}^{-1}$, respectively; Fig. 5B). Conversely, violaxanthin $\left(0.95 \pm 0.05 \mathrm{mg} \mathrm{L}^{-1} \mathrm{~d}^{-1}\right)$ and lutein $\left(1.83 \pm 0.12 \mathrm{mg} \mathrm{L}^{-1} \mathrm{~d}^{-1}\right)$ productions are highest at $170 \mu \mathrm{mol} \mathrm{m}^{-2} \mathrm{~s}^{-1}$ (Fig. 5B).

Taken together, these results point out a possible combination of high temperature of $35^{\circ} \mathrm{C}$ and a light intensity of $170 \mu \mathrm{mol} \mathrm{m}^{-2} \mathrm{~s}^{-1}$ 
under which Tetraselmis sp. CTP4 can simultaneously produce high amounts of lutein and $\beta$-carotene. Remarkably, this was possible despite their biosynthesis being differently regulated in response to a changing environment in the previous experiments. Furthermore, these higher contents of carotenoids were achieved in a very short period of only two days. Thus, in combination with the easy harvesting step of this microalga, this process becomes more economical and Tetraselmis sp. CTP4 may be considered a novel source of carotenoids. However, further studies are necessary to examine the production of carotenoids in industrial photobioreactors.

Microscopic observation of the cultures grown at a PFD of $33 \mu \mathrm{mol} \mathrm{m}^{-2} \mathrm{~s}^{-1}$ and $170 \mu \mathrm{mol} \mathrm{m}^{-2} \mathrm{~s}^{-1}$ under nitrogen repletion and depletion sampled on day 5 revealed the localization of carotenoids and lipids inside cells (Fig. 6). Cells under the higher light intensity and under nitrate depletion contained round intracellular structures corresponding to lipid droplets as reported previously $[13,14]$. As expected, total carotenoid content was low $\left(2.37 \pm 0.11 \mathrm{mg} \mathrm{g}^{-1} \mathrm{DW}\right)$, of which lutein accounted for $>50 \%\left(1.44 \pm 0.09 \mathrm{mg} \mathrm{g}^{-1} \mathrm{DW}\right)$. Under nitrate repletion conditions, however, almost no lipid droplets are visible; the carotenoid autofluorescence is diffuse throughout the cell. The total carotenoid content was 2.6 -fold higher than under depletion conditions $\left(6.15 \pm 0.54 \mathrm{mg} \mathrm{g}^{-1} \mathrm{DW}\right.$, Fig. 6), of which $\beta$-carotene accounted for $>50 \% \quad\left(3.07 \pm 0.2 \mathrm{mg} \mathrm{g}^{-1} \quad \mathrm{DW}\right)$. Conversely, at a PFD of $170 \mu \mathrm{mol} \mathrm{m}^{-2} \mathrm{~s}^{-1}$, the autofluorescence becomes more intense at specific spots inside the cell, becoming less diffuse. Furthermore, the carotenoids seem to be present only in the chloroplast, following its typical U-shape [14]. Compared with the lower light intensity, the total carotenoid content was lower $\left(4.31 \pm 0.54 \mathrm{mg} \mathrm{g}^{-1} \mathrm{DW}\right)$ while lutein content increased 2 -fold $\left(2.35 \pm 0.18 \mathrm{mg} \mathrm{g}^{-1} \mathrm{DW}\right)$. On closer examination of the overlay of DIC and autofluorescence micrographs, cells under nitrogen depletion appear to accumulate carotenoids outside of the lipid bodies, unlike Haematococcus pluvialis and Dunaliella salina, which accumulate astaxanthin and $\beta$-carotene in lipid bodies $[32,33]$. These findings strongly suggest that lutein and $\beta$-carotene are present in the thylakoid membrane rather than in lipid droplets in this species [7], which may explain why Tetraselmis cells do not accumulate carotenoids under the exact same conditions that favor lipid production. Therefore, it would be important to improve this microalga by selection of carotenoid-hyperproducing mutants, which may be able to accumulate carotenoids inside the lipid bodies.

\section{Conclusion}

This study evaluated the carotenoid profiles of Tetraselmis sp. CTP4 under a wide range of abiotic stress factors. A two-stage cultivation strategy could maximize the production of lutein, violaxanthin and $\beta$ carotene; during the first stage high biomass concentrations would be attained, and in the second stage, pigments would be induced by thermal and light upshifts. Although Tetraselmis microalgae are mainly used in aquaculture as feed, Tetraselmis sp. CTP4 could be an interesting candidate for the production of violaxanthin, lutein and $\beta$-carotene for nutraceutical and/or cosmeceutical applications, in particular when thermotolerant, robust microalgae are needed, such as the southern part of Portugal.

\section{Contributions}

The conception and design of the current manuscript was carried out by all authors. Data acquisition and analysis was primarily performed by Lisa Schüler (LS). Tamára Santos (TS), Hugo Pereira (HP), Paulo Duarte (PD) and Katkam Gangadhar (KG) assisted during the data collection and assembly of the data. Cláudia Florindo played an important role in data acquisition using fluorescence microscopy. Peter Schulze (PS) and Luísa Barreira (LB) analyzed the data with their statistical expertise. LS and João Varela (JV) performed the initial drafting of the article, and subsequent versions were drafted and reviewed by
LS, PS, HP, LB and JV. All authors contributed to the final approval of the article.

\section{Acknowledgements}

We would like to acknowledge the Light Microscopy Unit of CBMRUAlg.

\section{Funding}

The authors are indebted to the Foundation for Science and Technology (Portugal) for funding through the UID/Multi/04326/2019 research program and doctoral research grants awarded to LS, TS and HP (SFRH/BD/115325/2016, SFRH/BD/140143/2018, and SFRH/BD/ $105541 / 2014$, respectively). Further funding was provided by the 0055 ALGARED + 05 INTERREG V-A - España Portugal project. The Microscopy Unit was partially supported by national Portuguese funding PPBI-POCI-01-0145-FEDER-22122. Peter S.C. Schulze is a PhD student supported by Nord University.

\section{References}

[1] J. Matos, C. Cardoso, N.M. Bandarra, C. Afonso, Microalgae as healthy ingredients for functional food: a review, Food Funct. 8 (2017) 2672-2685, https://doi.org/10. 1039/C7FO00409E.

[2] A.P. Batista, L. Gouveia, N.M. Bandarra, J.M. Franco, A. Raymundo, Comparison of microalgal biomass profiles as novel functional ingredient for food products, Algal Res. 2 (2013) 164-173, https://doi.org/10.1016/j.algal.2013.01.004.

[3] P.J.L.B. Williams, L.M.L. Laurens, Microalgae as biodiesel \& biomass feedstocks: review \& analysis of the biochemistry, energetics \& economics, Energy Environ. Sci. 3 (2010) 554-590, https://doi.org/10.1039/b924978h.

[4] J.C. Varela, H. Pereira, M. Vila, R. León, Production of carotenoids by microalgae: achievements and challenges, Photosynth. Res. 125 (2015) 423-436, https://doi. org/10.1007/s11120-015-0149-2.

[5] L. Gouveia, A.E. Marques, J.M. Sousa, P. Moura, N.M. Bandarra, Microalgae source of natural bioactive molecules as functional ingredients, Food Sci. Technol. Bull. Funct. Foods. 7 (2010) 21-37, https://doi.org/10.1616/1476-2137.15884.

[6] G. Britton, H. Pfander, S. Liaaen-Jensen, Volume 4: natural functions, Carotenoids, Birkhäuser Verlag, 2008, pp. 189-211.

[7] L.M. Schüler, P.S.C. Schulze, H. Pereira, L. Barreira, R. León, J. Varela, Trends and strategies to enhance triacylglycerols and high-value compounds in microalgae, Algal Res. 25 (2017) 263-273, https://doi.org/10.1016/j.algal.2017.05.025.

[8] S. Rabbani, P. Beyer, J.v. Lintig, P. Hugueney, H. Kleinig, Induced $\beta$-carotene synthesis driven by triacylglycerol deposition in the unicellular alga Dunaliella bardawil, Plant Physiol. 116 (1998) 1239-1248, https://doi.org/10.1104/pp.116.4. 1239.

[9] F. Ahmed, K. Fanning, M. Netzel, W. Turner, Y. Li, P.M. Schenk, Profiling of carotenoids and antioxidant capacity of microalgae from subtropical coastal and brackish waters, Food Chem. 165 (2014) 300-306, https://doi.org/10.1016/j. foodchem.2014.05.107.

[10] AECOSAN, Authorisation to Market Tetraselmis chuii, (2014).

[11] C. Sansone, C. Galasso, I. Orefice, G. Nuzzo, E. Luongo, A. Cutignano, G. Romano, C. Brunet, A. Fontana, F. Esposito, A. Ianora, The green microalga Tetraselmis suecica reduces oxidative stress and induces repairing mechanisms in human cells, Nat. Publ. Gr. (2017) 1-12, https://doi.org/10.1038/srep41215.

[12] G. Di Lena, I. Casini, M. Lucarini, G. Lombardi-Boccia, Carotenoid profiling of five microalgae species from large-scale production, Food Res. Int. 120 (2019) 810-818, https://doi.org/10.1016/j.foodres.2018.11.043.

[13] H. Pereira, K.N. Gangadhar, P.S.C. Schulze, T. Santos, C.B. de Sousa, L.M. Schueler, L. Custódio, F.X. Malcata, L. Gouveia, J.C.S. Varela, L. Barreira, Isolation of a euryhaline microalgal strain, Tetraselmis sp. CTP4, as a robust feedstock for biodiesel production, Sci. Rep. 6 (2016) 35663, , https://doi.org/10.1038/srep35663.

[14] H. Pereira, J. Páramo, J. Silva, A. Marques, A. Barros, D. Maurício, T. Santos, P. Schulze, R. Barros, L. Gouveia, L. Barreira, J. Varela, Scale-up and large-scale production of Tetraselmis sp. CTP4 (Chlorophyta) for CO2 mitigation: from an agar plate to 100-m3 industrial photobioreactors, Sci. Rep. 8 (2018) 5112, https://doi. org/10.1038/s41598-018-23340-3.

[15] I. Dahmen-Ben Moussa, H. Chtourou, F. Karray, S. Sayadi, A. Dhouib, Nitrogen or phosphorus repletion strategies for enhancing lipid or carotenoid production from Tetraselmis marina, Bioresour. Technol. 238 (2017) 325-332, https://doi.org/10. 1016/j.biortech.2017.04.008.

[16] M. Dammak, B. Hadrich, R. Miladi, M. Barkallah, F. Hentati, R. Hachicha, C. Laroche, P. Michaud, I. Fendri, S. Abdelkafi, Effects of nutritional conditions on growth and biochemical composition of Tetraselmis sp, Lipids Health Dis. 16 (2017) 41, https://doi.org/10.1186/s12944-016-0378-1.

[17] K. Goiris, W. Van Colen, I. Wilches, F. León-Tamariz, L. De Cooman, K. Muylaert, Impact of nutrient stress on antioxidant production in three species of microalgae, Algal Res. 7 (2015) 51-57, https://doi.org/10.1016/j.algal.2014.12.002.

[18] H.-P. Tsai, L.-T. Chuang, C.-N.N. Chen, Production of long chain omega-3 fatty acids 
and carotenoids in tropical areas by a new heat-tolerant microalga Tetraselmis sp. DS3, Food Chem. 192 (2016) 682-690, https://doi.org/10.1016/j.foodchem.2015. 07.071 .

[19] M. Ruivo, A.N.A. Amorim, P. Cartaxana, Effects of growth phase and irradiance on phytoplankton pigment ratios: implications for chemotaxonomy in coastal waters, J. Plankton Res. 33 (2011) 1012-1022, https://doi.org/10.1093/plankt/fbr019.

[20] P.S.C. Schulze, C.F.M. Carvalho, H. Pereira, K.N. Gangadhar, L.M. Schüler, T.F. Santos, J.C.S. Varela, L. Barreira, Urban wastewater treatment by Tetraselmis sp. CTP4 (Chlorophyta), Bioresour. Technol. 223 (2017) 175-183, https://doi.org/ 10.1016/j.biortech.2016.10.027.

[21] I. Couso, M. Vila, J. Vigara, B.F. Cordero, M.Á. Vargas, H. Rodríguez, R. León, Synthesis of carotenoids and regulation of the carotenoid biosynthesis pathway in response to high light stress in the unicellular microalga Chlamydomonas reinhardtii, Eur. J. Phycol. 47 (2012) 223-232, https://doi.org/10.1080/09670262.2012. 692816.

[22] K.J.M. Mulders, P.P. Lamers, D.E. Martens, R.H. Wijffels, Phototrophic pigmen production with microalgae: biological constraints and opportunities, J. Phycol. 50 (2014) 229-242, https://doi.org/10.1111/jpy.12173.

[23] A. Ramos, S. Coesel, A. Marques, M. Rodrigues, A. Baumgartner, Isolation and characterization of a stress-inducible Dunaliella salina $L c y-\beta$ gene encoding a functional lycopene $\beta$-cyclase, Appl. Microbiol. Biotechnol. (2008) 819-828, https:// doi.org/10.1007/s00253-008-1492-4.

[24] P. Jahns, D. Latowski, K. Strzalka, Mechanism and regulation of the violaxanthin cycle: the role of antenna proteins and membrane lipids, Biochim. Biophys. Acta Bioenerg. 1787 (2009) 3-14, https://doi.org/10.1016/j.bbabio.2008.09.013.

[25] P. Bhosale, Environmental and cultural stimulants in the production of carotenoids from microorganisms, Appl. Microbiol. Biotechnol. 63 (2004) 351-361, https://doi. org/10.1007/s00253-003-1441-1.
[26] B.F. Cordero, I. Obraztsova, I. Couso, R. Leon, M.A. Vargas, H. Rodriguez, Enhancement of lutein production in Chlorella sorokiniana (chorophyta) by improvement of culture conditions and random mutagenesis, Mar. Drugs. 9 (2011) 1607-1624, https://doi.org/10.3390/md9091607.

[27] J.F. Sánchez, J.M. Fernández, F.G. Acién, A. Rueda, J. Pérez-Parra, E. Molina, Influence of culture conditions on the productivity and lutein content of the new strain Scenedesmus almeriensis, Process Biochem. 43 (2008) 398-405, https://doi. org/10.1016/j.procbio.2008.01.004.

[28] J.A. Del Campo, J. Moreno, H. Rodríguez, M. Angeles Vargas, J. Rivas, M.G. Guerrero, Carotenoid content of chlorophycean microalgae: factors determining lutein accumulation in Muriellopsis sp. (Chlorophyta), J. Biotechnol. 76 (2000) 51-59, https://doi.org/10.1016/S0168-1656(99)00178-9.

[29] M. Havaux, Carotenoids as membrane stabilizers in chloroplasts, 3 (1998) 147-151, https://doi.org/10.1016/S1360-1385(98)01200-X.

[30] T. Berner, Z. Dubinsky, K. Wyman, P.G. Falkowski, Photoadaptation and the "package" effect in Dunaliella tertiolecta (Chlorophyceae), J. Phycol. 25 (1989) 70-78, https://doi.org/10.1111/j.0022-3646.1989.00070.x.

[31] S.H. Ho, M.C. Chan, C.C. Liu, C.Y. Chen, W.L. Lee, D.J. Lee, J.S. Chang, Enhancing lutein productivity of an indigenous microalga Scenedesmus obliquus FSP-3 using light-related strategies, Bioresour. Technol. 152 (2014) 275-282, https://doi.org/ 10.1016/j.biortech.2013.11.031.

[32] L. Davidi, E. Shimoni, I. Khozin-Goldberg, A. Zamir, U. Pick, Origin of $\beta$-carotenerich Plastoglobuli in Dunaliella bardawil, Plant Physiol. 164 (2014) 2139-2156, https://doi.org/10.1104/pp.113.235119.

[33] S. Ota, A. Morita, S. Ohnuki, A. Hirata, S. Sekida, K. Okuda, Y. Ohya, S. Kawano, Carotenoid dynamics and lipid droplet containing astaxanthin in response to ligh in the green alga Haematococcus pluvialis, Sci. Rep. 8 (2018) 1-10, https://doi.org/ 10.1038/s41598-018-23854-w. 